\title{
Helping Learners Recognize, Diagnose, and Unravel Incompetence Traps to Achieve Synergistic Exploration-Exploitation in Classroom
}

\author{
Adelina Gnanlet, Dmitry Khanin \\ Graduate School of Business
}

\section{Abstract}

Sensemaking theory suggests that sensemaking may collapse when perception fails to detect weak signals of changes in the environment, cognition fails to appropriately categorize the new data coming from perception, and action fails to test the applicability of new concepts and schemas. Mindfulness-mindlessness theory warns us that routine practices based on low levels of exploration and exploitation may hinder performance. Finally, the theory of learning failure distinguishes between the traps of failure or overexploration and the traps of success or overexploitation. Combining and advancing these insights, we offer a typology of incompetence traps: (a) underexploration-underexploitation or mindlessness, (b) overexploration-underexploitation, and (c) overexploitation-underexploration. We examine their manifestations in perception, cognition, and action. Based on our analysis of how incompetence traps may hamper learning in management education, we give examples of how instructors may help students achieve synergistic explorationexploitation via informed vision (combining depth and multiple perspectives); perceptive thinking (combining theoretical, constraint-savvy knowledge and practical, context-savvy knowledge); and mindful action (developing and refining new and existing capabilities).

$\begin{array}{ll}\text { Original language } & \text { English } \\ \text { Pages (from-to) } & 684-712 \\ \text { Number of pages } & 29 \\ \text { Journal } & \text { Journal of Management Education } \\ \text { Volume } & 39 \\ \text { Issue number } & 6 \\ \text { State } & \text { Published - Dec 1 2015 }\end{array}$

Gnanlet, A., \& Khanin, D. (2015). Helping Learners Recognize, Diagnose, and Unravel Incompetence Traps to Achieve Synergistic Exploration-Exploitation in Classroom. Journal of Management Education, 39(6), 684-712. DOI: $\underline{10.1177 / 1052562914566682}$ 